\title{
Stress-induced magnetic and structural anisotropy of nanocrystalline Fe-based alloys
}

\author{
M. Ohnuma, ${ }^{1, a)}$ T. Yanai, ${ }^{2}$ K. Hono, ${ }^{1}$ M. Nakano, ${ }^{2}$ H. Fukunaga,${ }^{2}$ Y. Yoshizawa, ${ }^{3}$ and \\ G. Herzer ${ }^{4}$ \\ ${ }^{1}$ National Institute for Materials Science, 1-2-1 Sengen, Tsukuba 305-0047, Japan \\ ${ }^{2}$ Nagasaki University, Nagasaki 852-8521, Japan \\ ${ }^{3}$ Hitachi Metals Ltd., 2-15-17 Egawa, Shimamoto-cho, Osaka 618-0013, Japan \\ ${ }^{4}$ Vacuumschmelze GmbH \& Co. KG, D-63450 Hanau, Germany
}

(Received 26 March 2010; accepted 30 September 2010; published online 15 November 2010)

The structural anisotropy of $\mathrm{Fe}-\mathrm{Si}-\mathrm{B}-\mathrm{Nb}-\mathrm{Cu}$ nanocrystalline alloys annealed under tensile stress was studied by $\mathrm{x}$-ray diffraction techniques with transmission geometry. A clear difference was observed in the peak positions of the Fe-Si crystals under two different conditions: with the diffraction vector parallel or perpendicular to the applied stress. The strains calculated from the anisotropy of the peak positions show a linear response to the applied stress, independent of $\mathrm{Si}$ content, indicating that the observed structural anisotropy is due to a quenching of the elastic strain, not in the directional ordering of the $\mathrm{Fe}-\mathrm{Si}$ pair. The induced magnetic anisotropy energy is well explained by the residual strains and their magnetostrictions. () 2010 American Institute of Physics. [doi:10.1063/1.3506538]

\section{INTRODUCTION}

Fe-based nanocrystalline alloys prepared from amorphous precursors were introduced in $1988 .{ }^{1}$ Since then, they have been widely used as excellent soft magnetic materials. ${ }^{2}$ In these alloys, Fe crystals approximately $10 \mathrm{~nm}$ in size are formed by the annealing of amorphous ribbons. The origin of the extremely low coercivity is explained by the "random anisotropy model" in which the magnetocrystalline anisotropy is averaged out due to the small grain size relative to the exchange coupling length. ${ }^{3}$ Some applications, such as a choke coil or transformer, ${ }^{4}$ require a large magnetic anisotropy transverse to the magnetic path. For such applications, annealing in a magnetic field ${ }^{5,6}$ and/or under tensile stress ${ }^{7,8}$ is often applied. Annealing under stress is especially attractive due to the wide range of magnetic anisotropy which can be introduced by varying the amount of applied stress. ${ }^{7-10}$ The result is that the magnetic permeability can be tailored to a required value which is convenient for a particular industrial application. Therefore, since the 1970s, when amorphous and nanocrystalline ferromagnetic ribbons were produced by the rapid quench method, there have been a series of studies concerned with stress-induced anisotropy. ${ }^{7-10}$ In contrast, the structural origin of the magnetic anisotropy was unclear for about three decades until the anisotropy in the lattice plane was actually observed by transmission x-ray diffraction (t-XRD) techniques. ${ }^{11,12}$ This lattice plane anisotropy shows a linear response to the applied stress, which indicates that the anisotropy originates from residual elastic strain. However, the observed lattice spacing anisotropy may include some contribution from the directional ordering of $\mathrm{Fe}-\mathrm{Si}$ atomic pair effects introduced by stress annealing. In the present work we have investigated an alloy series with varying silicon content in order to study the magnitude of

\footnotetext{
${ }^{a)}$ Electronic mail: ohnuma.masato@nims.go.jp.
}

pair ordering effects via t-XRD. Differences in the anisotropy of different atomic planes are also discussed in order to understand the relationship between the bulk behavior and the observed changes in lattice planes of the ribbons.

\section{EXPERIMENTAL}

Amorphous ribbons of $\mathrm{Fe}_{73.5} \mathrm{Si}_{\mathrm{X}} \mathrm{B}_{22.5-\mathrm{X}} \mathrm{Nb}_{3} \mathrm{Cu}_{1}$ (X $=9,15.5)$ and $\mathrm{Fe}_{77.5} \mathrm{~B}_{15.5} \mathrm{Nb}_{3} \mathrm{Cu}_{1} 5 \mathrm{~mm}$ wide were prepared by the rapid quench method. ${ }^{1,5,10}$ The $\mathrm{Fe}_{73.5} \mathrm{Si}_{\mathrm{X}} \mathrm{B}_{22.5-\mathrm{X}} \mathrm{Nb}_{3} \mathrm{Cu}_{1}$ ribbons were heated to $550{ }^{\circ} \mathrm{C}$ and kept at that temperature for 20 min while applying different tensile stresses, and the annealing temperature was $450{ }^{\circ} \mathrm{C}$ for $\mathrm{Fe}_{77.5} \mathrm{~B}_{15.5} \mathrm{Nb}_{3} \mathrm{Cu}_{1}$. The details of the annealing settings have been described elsewhere. ${ }^{10}$ The t-XRD was measured using a conventional XRD system with Mo-K $\alpha$ radiation, an incident monochromator, and a solid state detector to cut the fluorescence effect. ${ }^{12}$ The incident $\mathrm{x}$-ray beam was aligned $\theta$ from the normal vector of the ribbons, and the diffracted beam was also aligned $\theta$ from the normal vector of the opposite side of the ribbons. Consequently, the diffraction vector q was fixed in the ribbon plane as schematically shown in Fig. 1. Two measurements were conducted for each sample: one for the measurement in which the diffraction vector is parallel to the ribbon direction (the same direction as the applied tensile stress), and the other for the diffraction vector parallel to the ribbon width direction, i.e., perpendicular to the stress direction. All of the t-XRD measurements were performed at room temperature after releasing the stress. The uniaxial magnetic anisotropy energy, $\mathrm{K}_{\mathrm{u}}$, was calculated from the anisotropy field, $\mathrm{H}_{\mathrm{k}}$, and the saturation magnetization, $\mathrm{B}_{\mathrm{s}}$, was measured at room temperature after releasing the stress (not reported in this paper). 


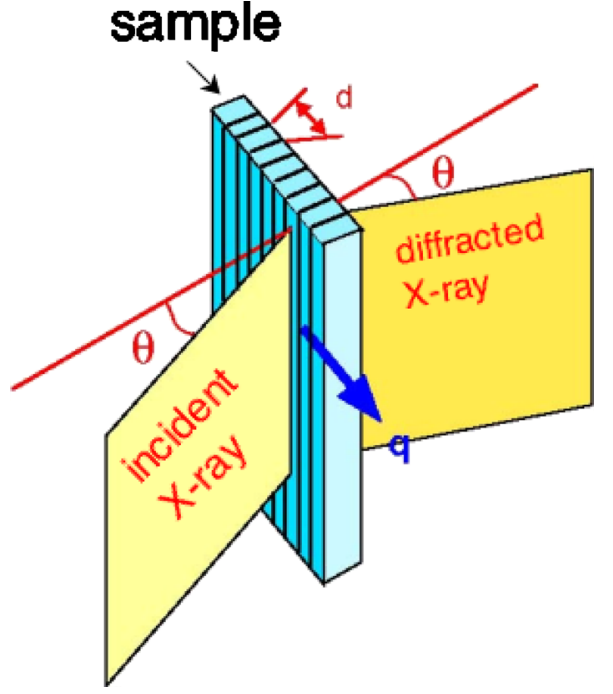

FIG. 1. (Color online) Schematic drawing of t-XRD geometry.

\section{RESULTS AND DISCUSSIONS}

Figure 2 shows the t-XRD profiles for the $\mathrm{Fe}_{77.5} \mathrm{~B}_{15.5} \mathrm{Nb}_{3} \mathrm{Cu}_{1}$ and $\mathrm{Fe}_{73.5} \mathrm{Si}_{9} \mathrm{~B}_{13.5} \mathrm{Nb}_{3} \mathrm{Cu}_{1}$ alloys annealed under different tensile stresses. A clear change of the peak position is observed even in the alloy without $\mathrm{Si}$, which indicates that the observed structural anisotropy is not related to $\mathrm{Fe}-\mathrm{Si}$ pair ordering. The measured values of the lattice spacing of the alloys annealed under different stresses are plotted together with previous results for $\mathrm{Fe}_{73.5} \mathrm{Si}_{15.5} \mathrm{~B}_{7} \mathrm{Nb}_{3} \mathrm{Cu}_{1}$ in Fig. 3. All of the data show a linear relationship, and their gradients are about the same for all of the alloys, almost independent of Si concentration. Therefore, it is concluded that the structural anisotropies observed in the lattice spacing of the alloys with and without $\mathrm{Si}$ are predominantly due to elastic residual strain, and the contribution of $\mathrm{Fe}-\mathrm{Si}$ pair ordering is negligible.

When the elastic strain exists in ferromagnetic materials, uniaxial magnetic anisotropy is induced due to the magnetoelastic effect. In the present experimental situation, we basically deal with a simple, uniaxial stress strain experiment for

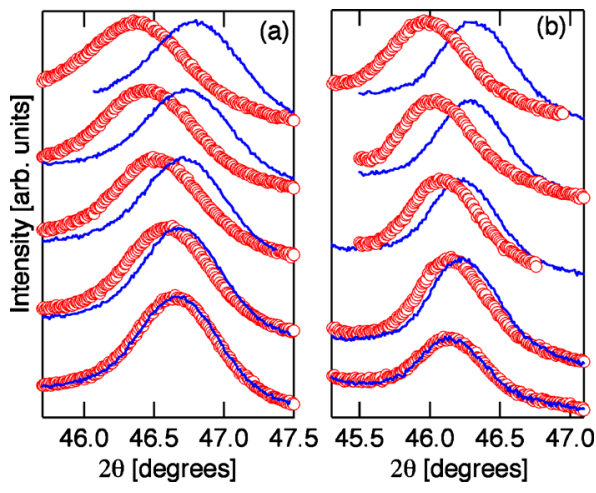

FIG. 2. (Color online) t-XRD profiles for (a) (620) plane of $\mathrm{Fe}_{3} \mathrm{Si}$ phase in $\mathrm{Fe}_{73.5} \mathrm{Si}_{9} \mathrm{~B}_{13.5} \mathrm{Nb}_{3} \mathrm{Cu}_{1}$ and (b) (310) plane of bcc-Fe phase in $\mathrm{Fe}_{77.5} \mathrm{~B}_{15.5} \mathrm{Nb}_{3} \mathrm{Cu}_{1}$ alloys annealed under different tensile stress. Circles and curves indicate t-XRD profiles with diffraction vector parallel and perpendicular to the applied stress, respectively. The applied stress is (a) 10, 102, 212, 332, and $469 \mathrm{MPa}$, (b) 10, 102, 207, 313, and $433 \mathrm{MPa}$, from bottom to top.

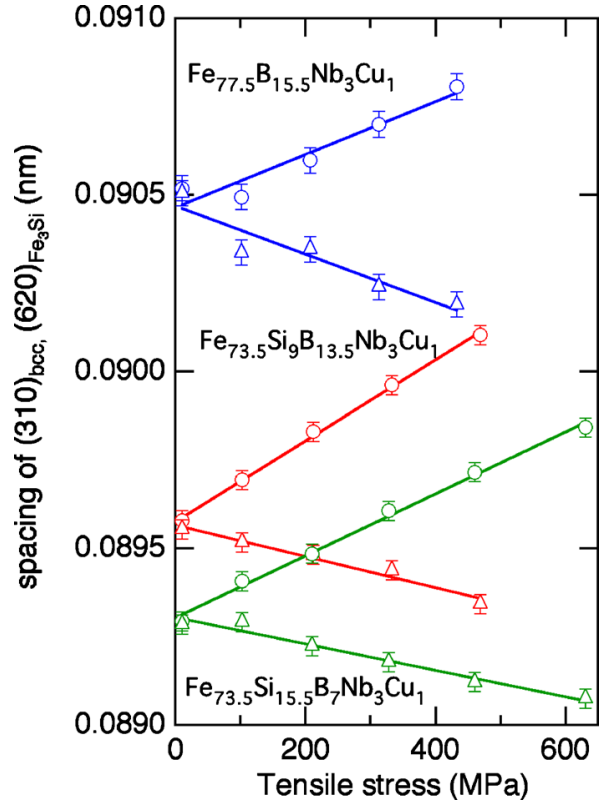

FIG. 3. (Color online) Lattice spacing of $\mathrm{Fe}_{73.5} \mathrm{Si}_{\mathrm{X}} \mathrm{B}_{22.5-\mathrm{X}} \mathrm{Nb}_{3} \mathrm{Cu}_{1} \quad(\mathrm{X}$ $=9,15.5)$ and $\mathrm{Fe}_{77.5} \mathrm{~B}_{15.5} \mathrm{Nb}_{3} \mathrm{Cu}_{1}$ alloys annealed under different stresses. Circles: lattice spacing, d, parallel to the applied stress. Triangles: d perpendicular to the applied stress.

an isotropic material. Furthermore, the structural correlation lengths for both the amorphous matrix and the randomly oriented crystallites are smaller than the ferromagnetic exchange length. ${ }^{15}$ Thus, exchange interaction effectively reduces the magnetostriction tensor to an isotropic fourth rank tensor $^{15}$ characterized by a single magnetostriction coefficient, the saturation magnetostriction constant $\lambda_{\mathrm{s}}$. Accordingly, the theoretical description of the average magnetoelastic interaction can be simplified drastically. As a result the induced magnetic anisotropy energy constant, $\mathrm{K}_{\mathrm{u}}$, can be related to the strain as follows:

$$
K_{u}=-\frac{3}{2} E e_{\|} \lambda_{s},
$$

where $E, e_{\|}$, and $\lambda_{\mathrm{s}}$ are the elastic modulus, elastic strain parallel to the stress, and saturation magnetostriction, respectively. By convention, $K_{\mathrm{u}}>0$ hereby refers to a magnetic easy perpendicular to the strain axis. As described above, the observed anisotropy corresponds directly to residual elastic strain. Therefore, strain parallel to the applied stress for the sample annealed under $x \mathrm{MPa}, e_{\|}^{x \mathrm{MPa}}$ can be defined by the following equation:

$$
e_{\|}^{x \mathrm{MPa}}=\frac{d_{\|}^{x \mathrm{MPa}}-d_{\|}^{0 \mathrm{MPa}}}{d_{\|}^{0 \mathrm{MPa}}},
$$

where, $d_{\|}^{x \mathrm{MPa}}$ and $d_{\|}^{0 \mathrm{MPa}}$ is the lattice spacing of the samples annealed under $x \mathrm{MPa}$ and $0 \mathrm{MPa}$ obtained from t-XRD peak positions, respectively. Due to the annealing facility used, the value of $\mathrm{d}_{\|}^{10 \mathrm{MPa}}$ annealed under $10 \mathrm{MPa}$ instead of $0 \mathrm{MPa}$ is used here-for the minimum stress value, which yields the isotropic peak positions shown in Fig. 2.

The relationship between $K_{u}$ and $e_{\|}$is again linear, as shown in Fig. 4. This means that Eq. (1) is applicable, and therefore, the induced magnetic anisotropy is magnetoelastic in origin. Taking the small effect of Si content on the elastic 


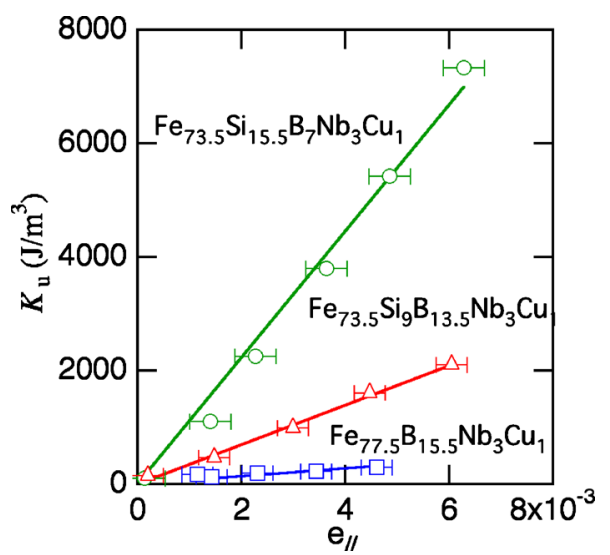

FIG. 4. (Color online) Anisotropy energy $\mathrm{K}_{\mathrm{u}}$ vs elongation determined from (620) or (310) plane for $\mathrm{Fe}_{73.5} \mathrm{Si}_{\mathrm{X}} \mathrm{B}_{22.5-\mathrm{X}} \mathrm{Nb}_{3} \mathrm{Cu}_{1} \quad(\mathrm{X}=9,15.5)$ and $\mathrm{Fe}_{77.5} \mathrm{~B}_{15.5} \mathrm{Nb}_{3} \mathrm{Cu}_{1}$ alloys, parallel to applied stress, $e_{\| \cdot}$. Circles: $\mathrm{x}=15.5$, triangles: $\mathrm{x}=9$, squares: $\mathrm{Fe}_{77.5} \mathrm{~B}_{15.5} \mathrm{Nb}_{3} \mathrm{Cu}_{1}$ alloys.

modulus into account, the difference of the gradient is mainly attributable to the $\lambda_{\mathrm{s}}$, which is the largest for the $\mathrm{Fe}_{73.5} \mathrm{Si}_{15.5} \mathrm{~B}_{7} \mathrm{Nb}_{3} \mathrm{Cu}_{1}$ alloy.

To evaluate the value of $\lambda_{\mathrm{s}}$, an evaluation of the Young's modulus is necessary. The simplest model of stress-strain distribution in the polycrystalline system can be either uniform strain or uniform stress distributions. In the former model, each grain shows same elongation, while the each grain elongate under the uniform stress. Usually most of the polycrystalline system is in between two models. To clarify our case, we measure different lattice strains parallel to tensile stress. Figure 5 shows the t-XRD results for four different indexes of the (440), (620), (444), and (642) planes of the $\mathrm{Fe}_{3} \mathrm{Si}$ phase in an $\mathrm{Fe}_{73.5} \mathrm{Si}_{15.5} \mathrm{~B}_{7} \mathrm{Nb}_{3} \mathrm{Cu}_{1}$ alloy annealed under 10, 213, and $461 \mathrm{MPa}$. The observed anisotropy of the planes shows a large difference depending on the index of the planes, even in samples annealed under the same stress. The diffraction peak for (440), (620), and (642) shows clear anisotropy, while the peak for (444) shows little anisotropy under all applied stresses. Using Eq. (2), the strain, $e_{\|}$, for each index plane is evaluated and plotted in Fig. 6. The results show the different strains depending on the index, indicating that the studied alloy is far from uniform strain condition. Table I shows the elastic modulus for each direction from the gradient assuming an elastic response to the applied stress. Obtained values are about 100,400 , and $500 \mathrm{GPa}$ in

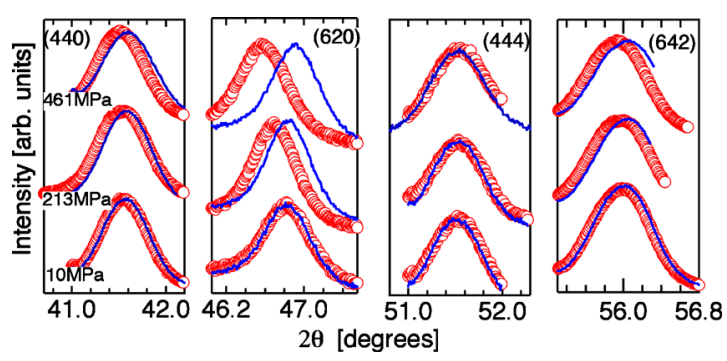

FIG. 5. (Color online) XRD profiles of four different index planes [(440), (620) (444) and (642)] of $\mathrm{Fe}_{3} \mathrm{Si}$ phase in $\mathrm{Fe}_{73.5} \mathrm{Si}_{15.5} \mathrm{~B}_{7} \mathrm{Nb}_{3} \mathrm{Cu}_{1}$ alloy annealed under 10, 213, and $461 \mathrm{MPa}$, from bottom to top. Circles and curves indicate t-XRD profiles with diffraction vector parallel and perpendicular to the applied stress, respectively.

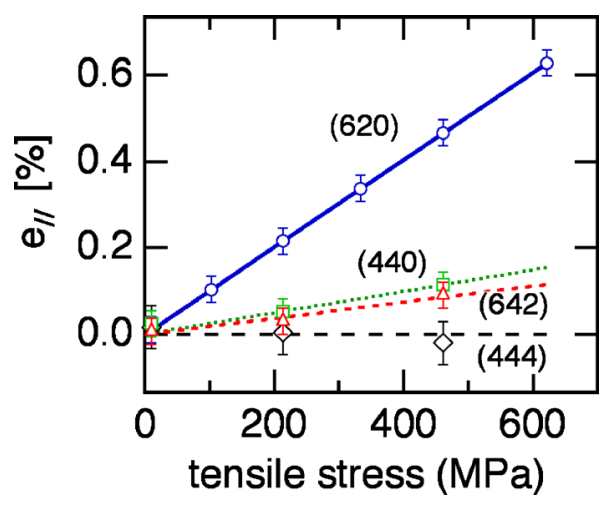

FIG. 6. (Color online) Strains, $e_{\|}$, for different index planes measured parallel to applied stress plotted as a function of applied stress during annealing. circles: (620), squares: (440), triangles: (642), diamonds: (444) planes.

the [310], [110], and [321] directions, respectively. The small change of the (444) planes suggests that the elastic modulus for the [111] direction is even larger than in the [321] direction. The difference in the elastic modulus corresponds to the difference of elastic modulus for single crystals. For the cubic system, ${ }^{13}$ the specific modulus for single crystalline $h \mathrm{kl}$ plane, $E_{h k l}$, can be described as

$$
1 / E_{h k l}=S_{11}-2\left(S_{11}-S_{12}-1 / 2 S_{44}\right) A_{h k l},
$$

where $S_{\mathrm{ij}}$ in the single crystal compliance tensor in collapsed matrix notation and $A_{h k l}$ is

$$
A_{h k l}=\left(h^{2} k^{2}+h^{2} l^{2}+k^{2} l^{2}\right) /\left(h^{2}+k^{2}+l^{2}\right)^{2} .
$$

Using Eqs. (3) and (4), and the published dependence of $S_{11}, S_{12}, S_{44}$ on $\mathrm{Si}$ concentration, ${ }^{14} E_{h k l}$ for Fe-20at. $\% \mathrm{Si}$ single crystal can be calculated and listed in Table I. As show in Table I, the observed modulus relates to the elastic nature in each direction, qualitatively, i.e., [310] direction is softer direction, [110] and [321] are similar values within the error, and [111] is the hardest directions among them. These facts suggest that the residual strain is formed under a uniform stress condition in which all grains are under the same stress. Therefore, depending on the crystalline direction of each nanosingle crystal, the elastic response is different parallel to the tensile stress. This is reasonable for the case where the residual amorphous phase with an isotropic nature already in the plastic region at high temperature is a medium for uniform stress distribution. There are still some differences between observed and calculated elastic modulus. This is partially attributed to the fact that the amorphous matrix exceeds the elastic limit due to softening, which is characteristic of

TABLE I. Observed and calculated elastic modulus, $E_{h k l}^{o b s}, E_{h k l}^{c a l c}$ and $A_{h k l}$ for Fe-20at. \%Si bec crystals.

\begin{tabular}{cccl}
\hline \hline Index of planes & $\begin{array}{c}E_{h k l}^{o b s} \\
(\mathrm{Gpa})\end{array}$ & $\begin{array}{c}E_{h k l}^{\text {calc }} \\
(\mathrm{Gpa})\end{array}$ & \multicolumn{1}{c}{$A_{h k l}$} \\
\hline 100 & $\ldots$ & 103 & 0 \\
111 & $\ldots$ & 313 & 0.333 \\
220 & $403+/-50$ & 208 & 0.25 \\
310 & $99+/-20$ & 126 & 0.09 \\
321 & $535+/-60$ & 208 & 0.25 \\
\hline \hline
\end{tabular}


TABLE II. Volume fraction $v^{\mathrm{Fe}-\mathrm{Si}}$ and $\mathrm{Si}$ content in $\mathrm{Fe}-\mathrm{Si}$ crystals evaluated from mass balance of Eq. (5) Corresponding Elastic modulus for [310] direction calculated from Eqs. (3) and (4) and obtained $\lambda$ s are also listed.

\begin{tabular}{lcccc}
\hline \hline Alloy comp. & $v^{\mathrm{Fe}-\mathrm{Si}}$ & $\begin{array}{c}\text { Si content } \\
\text { in Fe-Si } \\
\text { (at. \%) }\end{array}$ & $\begin{array}{c}E_{310} \\
(\mathrm{Gpa})\end{array}$ & $\begin{array}{c}\lambda_{\mathrm{s}} \\
(\mathrm{ppm})\end{array}$ \\
\hline $\mathrm{Fe}_{77.5} \mathrm{~B}_{15.5} \mathrm{Nb}_{3} \mathrm{Cu}_{1}$ & 0.49 & 0 & 153 & -0.6 \\
$\mathrm{Fe}_{73.5} \mathrm{Si}_{9} \mathrm{~B}_{13.5} \mathrm{Nb}_{3} \mathrm{Cu}_{1}$ & 0.56 & 16 & 126 & -3.3 \\
$\mathrm{Fe}_{73.5} \mathrm{Si}_{15.5} \mathrm{~B}_{7} \mathrm{Nb}_{3} \mathrm{Cu}_{1}$ & 0.77 & 20 & 126 & -7.7 \\
\hline \hline
\end{tabular}

non-crystalline materials. Therefore, the effective cross section that behaves elastically is smaller than that of ribbons. In addition, observed elastic moduli, $E_{h k l}^{o b s}$ of $\mathrm{Fe}-\mathrm{Si}$ crystals correspond to those of the annealing temperature where the stress is loaded. They can be different from $E_{h k l}^{c a l c}$ which are calculated from the $S_{i j}$ values obtained at room temperature. In contrast, because $K_{u}$ is measured at room temperature, the elastic modulus at room temperature should be used for the analysis of the magnetoelastic effect. Therefore, calculated $E_{310}^{c a l}$ is used as the best approximation for discussing the relationship between $K_{u}$ and $e_{\|}$determined from (620)/(310) planes in the following part.

The strains obtained from the XRD profiles are purely from bcc crystals. In contrast, the anisotropic energy, $K_{u}$, obtained from magnetic measurements corresponds to one from both bcc and amorphous phases. Thus, the effect of volume fraction on $\mathrm{K}_{\mathrm{u}}$ must be taken into account following the method proposed by Herzer. ${ }^{8,15}$ In this model, the saturation magnetostriction of the ribbon, $\lambda_{\mathrm{s}}^{\text {ribbon }}$, is given by the simple sum of the magnetostriction of the Fe-Si nanocrystals, $\lambda_{\mathrm{s}}^{\mathrm{Fe}-\mathrm{Si}}$, and that of the remaining amorphous material, $\lambda_{\mathrm{s}}^{\mathrm{AM}}$, weighted by their volume fractions: ${ }^{8}$

$$
\lambda_{\mathrm{s}}^{\text {ribbon }}=v^{\mathrm{Fe}-\mathrm{Si}} \lambda_{\mathrm{s}}^{\mathrm{Fe}-\mathrm{Si}}+\left(1-v^{\mathrm{Fe}-\mathrm{Si}}\right) \lambda_{\mathrm{s}}^{\mathrm{AM}} .
$$

Here, $v^{\mathrm{Fe}-\mathrm{Si}}$ is the volume fraction of the Fe-Si nanocrystals, which can be evaluated from the valance of the chemical composition under the assumption that perfect partitioning of $\mathrm{Si}, \mathrm{B}, \mathrm{Nb}$, and $\mathrm{Cu}$ to the constituent phases occurs as follows:

$$
\begin{aligned}
\mathrm{Fe}-\mathrm{Si}-\mathrm{B}-\mathrm{Nb}-\mathrm{Cu} \rightarrow & v^{\mathrm{Fe}-\mathrm{Si}} \mathrm{Fe}_{1-\mathrm{y}} \mathrm{Si}_{\mathrm{y}}+\left(0.99-v^{\mathrm{Fe}-\mathrm{Si}}\right) \\
& \times\left(\mathrm{Fe}_{1-\mathrm{a}} \mathrm{Nb}_{\mathrm{a}}\right)_{n} \mathrm{~B}+0.01 \mathrm{Cu} .
\end{aligned}
$$

Here, y is the Si content in the Fe-Si nanocrystals, and $a$ is the $\mathrm{Nb}$ content in the remaining B-rich amorphous phase. The value of 2.2 is adopted from Ref. 15 for $n$. Consequently, the volume fraction and the $\mathrm{Si}$ content in the $\mathrm{Fe}-\mathrm{Si}$ phase are evaluated and listed in Table. II. In order to understand what happens on average along the applied stress axis, the contribution of the $\mathrm{Fe}-\mathrm{Si}$ phase to the magnetic anisotropy, $K_{\mathrm{u}}^{\mathrm{Fe}-\mathrm{Si}}$ can be correlated with the residual stress of $\mathrm{Fe}-\mathrm{Si}$ phase, $\sigma_{\|}^{\mathrm{Fe}-\mathrm{Si}}$ parallel to the applied stress direction. For evaluating average $\sigma_{\|}^{\mathrm{Fe}-\mathrm{Si}}, e_{\|}$determined from $(620) /(310)$ peak and the elastic modulus, $E_{310}$ is used under the assumption of uniform stress condition, i.e., $\sigma_{\|}^{\mathrm{Fe}-\mathrm{Si}}=e_{\|} E_{310}$. Therefore, $K_{\mathrm{u}}^{\mathrm{Fe}-\mathrm{Si}}$ can now be rewritten using Eqs. (1) and (3) as follows (cf [8]):

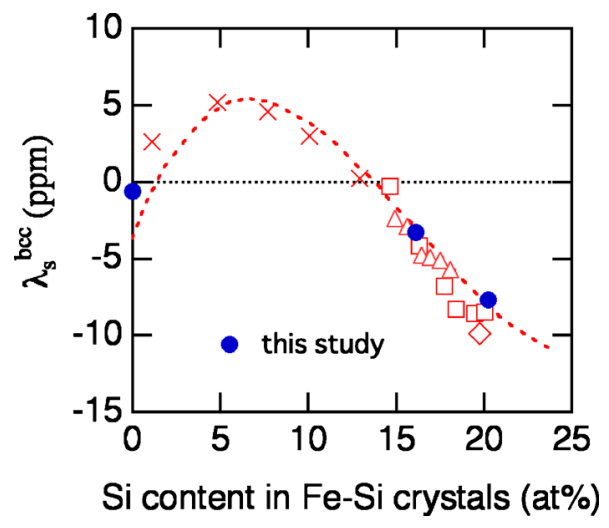

FIG. 7. (Color online) Dependence of $\lambda_{\mathrm{s}}$ on $\mathrm{Si}$ content in Fe-Si crystals. Solid circles: $\lambda_{\mathrm{s}}$ determined in this study. Other markers: $\lambda_{\mathrm{s}}$ adopted from Ref. 8 in different $\mathrm{Si}$ and $\mathrm{B}$ content of $\mathrm{Fe}-\mathrm{Si}-\mathrm{B}-\mathrm{Nb}-\mathrm{Cu}$ nanocrystalline alloys (cross: 18.5; triangle: 20.5; square: 22.5 ; diamond: 23.5 at $\%$ of the sum of $\mathrm{Si}$ and $\mathrm{B}$ content in the alloys). Dotted lines: polycrystalline $\mathrm{Fe}-\mathrm{Si}$ alloys (Ref. 16).

$$
K_{\mathrm{u}}^{\mathrm{Fe}-\mathrm{Si}}=-\frac{3}{2} v^{\mathrm{Fe}-\mathrm{Si}} E_{310} e_{\|} \lambda_{s}^{\mathrm{Fe}-\mathrm{Si}} .
$$

Consequently, the saturation magnetostriction, $\lambda_{\mathrm{s}}^{\mathrm{Fe}-\mathrm{Si}}$, can be calculated from the gradient of the lines shown in Fig. 4 using $v^{\mathrm{Fe}-\mathrm{Si}}$ and $E_{310}$ calculated from Eqs. (3) and (4) with the elastic constrains of bcc Fe-Si for corresponding Si content. The $\lambda_{\mathrm{s}}^{\mathrm{Fe}-\mathrm{Si}}$ values obtained are $-0.6 \mathrm{ppm},-3.3 \mathrm{ppm}$, and $-7.7 \mathrm{ppm}$, respectively, and listed in Table II together with each $\mathrm{E}_{310}$. Those values are plotted together with the results for the $\mathrm{Fe}-\mathrm{Si}$ phase in $\mathrm{Fe}-\mathrm{Si}-\mathrm{B}-\mathrm{Nb}-\mathrm{Cu}$ alloys ${ }^{8}$ and for conventional $\mathrm{Fe}-\mathrm{Si}$ alloys ${ }^{16}$ in Fig. 7. Although simple models are used for evaluating the Si content and the volume fraction of $\mathrm{Fe}-\mathrm{Si}$ crystals, the results show excellent agreement with the previous data, again indicating that the induced magnetic anisotropy is a magnetoelastic effect.

\section{SUMMARY}

The anisotropy of the lattice spacing in $\mathrm{Fe}-\mathrm{Si}$ nanocrystals of $\mathrm{Fe}-\mathrm{Si}-\mathrm{B}-\mathrm{Nb}-\mathrm{Cu}$ alloys annealed under different stresses was studied, resulting in the following:

(1) All alloys show structural anisotropy when annealed under a certain stress.

(2) Independent of $\mathrm{Si}$ content, a linear response between applied stress and strain was determined from the structural anisotropy.

(3) The elastic constant determined from the gradient of the strain-applied stress plot shows a strong dependence on the lattice plane. The origin of the difference can be understood from the anisotropic elastic nature of each single crystal. It also indicates that the nanocrystals in the alloys are under uniform stress conditions during annealing.

(4) The dependence of the magnetic anisotropy on composition is explained by the corresponding variation of the local magnetostriction, $\lambda_{\mathrm{s}}^{\mathrm{Fe}-\mathrm{Si}}$ of the crystallites. The $\lambda_{\mathrm{s}}^{\mathrm{Fe}-\mathrm{Si}}$ determined from structural anisotropy agrees well with bulk values in conventional $\mathrm{Fe}-\mathrm{Si}$ and nanocrystalline alloys. 


\section{ACKNOWLEDGMENT}

This work was partially supported by KAKENHI JSPS18360340.

${ }^{1}$ Y. Yoshizawa, S. Oguma, and K. Yamauchi, J. Appl. Phys. 64, 6044 (1988).

${ }^{2}$ G. Herzer, M. Vazquez, M. Knobel, A. Zhukov, T. Reininger, H. A. Davis, R. Grössinger, and J. L. Sanchez Ll, J. Magn. Magn. Mater. 294, 252 (2005).

${ }^{3}$ G. Herzer, IEEE Trans. Magn. 25, 3327 (1989).

${ }^{4}$ J. Petzold, J. Magn. Magn. Mater. 242-245, 84 (2002).

${ }^{5}$ Y. Yoshizawa and K. Yamauchi, IEEE Trans. Magn. 5, 1070 (1990).

${ }^{6}$ G. Herzer, Mater. Sci. Eng., A 182, 876 (1994).

${ }^{7}$ L. Kraus, K. Zaveta, O. Heczko, P. Duhaj, G. Vlasak, and T. Schneider, J. Magn. Magn. Mater. 112, 275 (1992).

${ }^{8}$ G. Herzer, IEEE Trans. Magn. 30, 4800 (1994).
${ }^{9}$ B. Hofmann and H. Kronmüller, J. Magn. Magn. Mater. 152, 91 (1996).

${ }^{10}$ H. Fukunaga, N. Furukawa, H. Tanaka, and M. Nakano, J. Appl. Phys. 87, 7103 (2000)

${ }^{11}$ M. Ohnuma, K. Hono, T. Yanai, H. Fukunaga, and Y. Yoshizawa, Appl. Phys. Lett. 83, 2859 (2003)

${ }^{12}$ M. Ohnuma, K. Hono, T. Yanai, H. Fukunaga, and Y. Yoshizawa, Appl. Phys. Lett. 86, 152513 (2005).

${ }^{13}$ M. R. Daymond, M. A. M. Bourke, R. B. Von Dreele, B. Clausen, and T. Lorentzen, J. Appl. Phys. 82, 1554 (1997).

${ }^{14}$ R. F. S. Hearmon, 1.2.1 Elastic constants, Landolt-Börnstein, New Series Group III, Vol. 11, edited by K.-H. Hellwege, (Springer-Verlag, Berlin, 1979), pp. 10-16.

${ }^{15} \mathrm{G}$. Herzer, Handbook of Magnetic Materials, edited by K. H. J. Buschow (Elsevier Science, New York, 1997), Vol. 10, Chap. 3, pp. 415-462.

${ }^{16}$ T. Yamamoto, The Development of Sendust and Other Ferromagnetic Alloys (Komiyama Pringting, Chiba, Japan, 1980), pp. 27-29. 